BMJ Open Sport \& Exercise Medicine

\title{
From the safety net to the injury prevention web: applying systems thinking to unravel injury prevention challenges and opportunities in Cirque du Soleil
}

Caroline Bolling, ${ }^{\oplus 1}$ Jay Mellette, ${ }^{2}$ H Roeline Pasman, ${ }^{1}$ Willem van Mechelen, ${ }^{1,3,4,5}$ Evert Verhagen ${ }^{1,3}$

\section{ABSTRACT}

Objective We undertook this qualitative study within an international circus company-Cirque du Soleil-to explore the narrative of artists and the artistic team in regards to injuries and their prevention and to describe the prevention of injuries from a systems thinking lens.

Methods Focus groups (FG) with artists and semistructured individual interviews with the artistic team were conducted in six selected shows. The structure of the interviews and FGs concerned the themes: 'injury', 'injury-related factors' and 'injury prevention'. Data were analysed through comparative data analysis based on Grounded Theory. Concept mapping and systems thinking approaches were used to design a map of participants' views on how to prevent injuries.

Results Injury was mainly described based on performance limitation. The factors mostly mentioned to be related to injury occurrence were physical load factors. Many of these factors were said to be connected and to influence each other. Injury prevention was mapped as a multilevel system, composed by artist-related factors (eg, technique and life style) and extrinsic factors (eg, touring conditions and equipment) that integrate different strategies and stakeholders.

Conclusion Our study reinforces the importance of multilevel injury prevention approaches with shared responsibility and open communication among stakeholders.

\section{INTRODUCTION}

Circus is a performing art in which the artist is exposed to high physical workloads during preparation and performance. As a consequence, circus artists are at high risk of injury and studies have reported injury incidences comparable to sports, ranging from 7.3 to 9.7 injuries per 1000 artist performances. ${ }^{1-3}$ Most of circus injury prevention evidence concerns dancers' and musicians' health, ${ }^{4}$ both performing arts with succinctly different injury rates and spectra when compared
What are the new findings?

Systems thinking and qualitative research can be applied to understand injury prevention as a complex system.

- A system map can illustrate injury prevention as a multilevel system and identify the stakeholders directly and indirectly related to the injury prevention and their interconnections.

- Injury prevention as a complex system requires an effort of multiple stakeholders working together and sharing the responsibility to prevent injuries.

How might it impact on clinical practice in the near future?

Injury prevention is not restricted to stakeholders that deal directly with artists, and multiple departments can influence injury prevention due to the interconnection between elements of the system.

- The injury prevention in an organisation like Cirque du Soleil can be compared with other sports settings, and our approach can be applied to understand sports contexts.

with circus. Historically, injury prevention measures for circus artists have been reported rarely beyond safety measures for accident avoidance purposes. ${ }^{5}$

Sports injuries are a complex phenomenon. ${ }^{67}$ Hence, it is important to explore the context of injuries and their associated (causal) factors first when seeking to reduce risk of injury. ${ }^{8}{ }^{9}$ The circus environment combines artistic and athletic performance, consists of multicultural teams and mixes high-level artists with acrobats and former athletes. The artists perform their magic in an occupational environment that includes various stakeholders with different 
responsibilities, working in different departments and management structures.

A systems approach, already applied in tobacco control and obesity prevention, ${ }^{10}{ }^{11}$ can help us understand the contextual complexity. Therefore, we combined the systems approach with qualitative research methods to listen to artists and their entourage-coaches, health professionals and artistic directors (AD) - in a circus setting. Our goal was to better understand the specific context in which injury occurs and map opportunities and challenges to prevent injuries.

\section{METHODS \\ Setting}

Cirque du Soleil is a Canadian entertainment company with a 30-year history is the largest theatrical producer in the world. The company employs over 5000 people on four continents to perform 23 shows concurrently. ${ }^{12}$ Over 1000 artists from over 40 different countries and diverse backgrounds (traditional circus artists, former professional athletes, musicians and dancers) perform a variety of circus disciplines. ${ }^{13}$ Cirque du Soleil shows involve circus artists who perform in individual 'solo' acts or in group acts. Beyond an artist's primary act, the artist also performs 'cues', that is, supplementary mini performances or activities during a show. A typical workweek for an artist consists of an average of 8-10 shows, spread over 5-6 consecutive days. Individual artists or group acts can have 'rotations' to adjust to workload and logistical considerations. Some shows are always performed in the same theatre (ie, residential shows (RS)). Other shows travel around the world. These touring shows (TS) can have varying formats, which can be a traditional 'Big Top' (a circus tent), staying in a particular city for two or 3 months on average or an 'Arena', staying in a particular city for an average of 1 or 2 weeks.

\section{Participants}

We studied a convenience sample made up of participants from two RS and four TS. This covered a variety of show formats including; 'big top', arena and RS. The specific show choice was based on the shows' schedule and the availability of cast and staff.

The main stakeholders of the artistic team (ie, those dealing directly with artists) within each selected show were invited to participate in a face-to-face interview. The sample included 6 head coaches (HC), 12 physiotherapists and athletic trainers-so-called Performance Medicine therapist (Pmed)-and $6 \mathrm{AD}$. All agreed to participate, but one Pmed was not available on the scheduled interview day due show demands.

All artists of selected shows were informed and invited to participate voluntarily in a focus group (FG) session. To guarantee a sample representative of the cast diversity in the show, artists from different backgrounds, cultures and disciplines were also personally invited by the Pmeds. A total of 64 artists participated in 7 FGs. Due to logistical reasons at one show, two FGs of five artists each had to be organised. At the other shows 1 FG was organised, varying in size from 9 to 13 artists.

All participants provided verbal audio-recorded informed consent and had confidentiality guaranteed.

\section{Data collection}

The interviews and FGs were conducted between July and December 2016 in different countries, depending on the location of the show at that time. The main author (CB) visited the shows and for 2 days, in each show, performed all the interviews and FGs. The structure of the interviews and FGs contemplated main themes like 'injury', 'injury-related factors' and 'injury prevention'. The interview guide included the following questions:

-What do you consider an injury (ie, injury definition)?

- Which factors influence the injury occurrence?

- Can injuries be prevented? How can injuries be prevented?

- Who is responsible to prevent injuries?

- Why would you be interested to prevent injury?

- Which injury prevention strategies do you apply and why?

After six shows, the same themes were repeated and no additional data was added, indicating that saturation had been reached.

All interviews and FGs were conducted onsite in a private room to ensure confidentiality. The individual interviews lasted on average $32 \mathrm{~min}$ (range: $22-45 \mathrm{~min}$ ). The average duration of FGs was 68 min (range: 52-86 $\mathrm{min}$ ). For the FGs, questions were asked in an interactive group setting, where participants were free to interact and to share ideas with other group members. A trained researcher $(\mathrm{CB})$ was the moderator for each FG.

\section{Data analysis}

All interviews and FGs were audio-recorded and transcribed verbatim by the main author $(\mathrm{CB})$. Any personal information or information that was deductible to an individual was anonymised during transcription. The data analysis flow is depicted in figure 1. Data were analysed using principles of Grounded Theory. ${ }^{14} 15$ This is a systematic inductive method that, through gathering, analysing and synthetizing data, generates main concepts to develop a theory. Initially, to synthesise the content of the interviews and FGs, the first author conducted open coding by creating codes, based on the repeated ideas and elements that had been extracted from the data. After agreement with a second coder (EV), all codes were re-reviewed and grouped into concepts and then into categories through applying constant comparison analysis. $^{1617}$

After consensus, main elements were grouped in categories. Then, concept mapping was applied to reduce the data and to analyse interconnections between categories. A concept map is a diagram that depicts suggested relationships between concept categories and that helps to visualise and organise the data. ${ }^{18}$ The first raw concept map plots the main concepts and the interconnections 

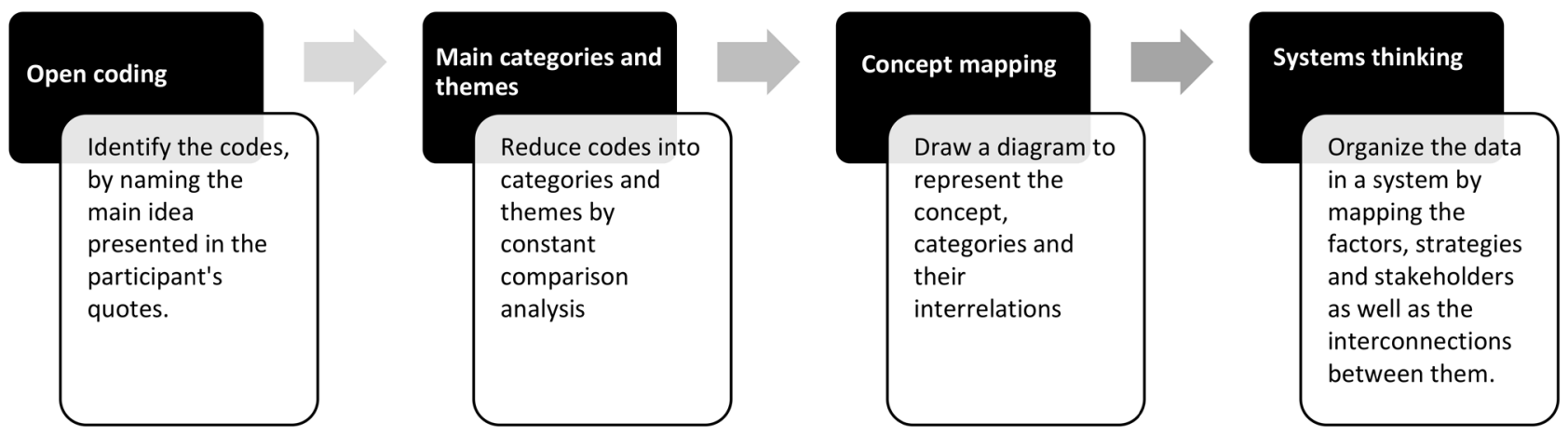

Figure 1 Data analysis flowchart.

without a specific structure. Thereafter, a systems map was developed by organising the interconnections of the previous map in a multilevel structure. A systems map is a visual description of the structure of an organisation with the different actors involved and their mutual links and flows through the system. Using a systems thinking approach, connections were identified between the categories, stakeholders and processes of the system. ${ }^{11} 19$ Subsequently, a system map was designed to describe the individuals and elements involved in injury prevention and their interconnections.

\section{RESULTS}

Injury definition

The stakeholders defined injury in different ways based on injury consequences. The most mentioned description of an injury was as 'a limitation that hampers an optimal performance'. The necessity to modify training and show performances was described as a common consequence of an injury, while missed training or performance was acknowledged as an easy descriptor of injury. The impact on show quality was mentioned as a consequence of injury, especially by HC and ADs. Although pain was mentioned as a part of injury, it was not described as a prerequisite to be classified as being injured (ie, injuries can also affect an individual without pain, and not every pain classifies as injury). The main identified codes related to the definition and description of injury are presented in table 1 , with respective quotes.

\section{Factors related to injury occurrence}

The various stakeholders mentioned a wide variety of injury risk factors. Many times, when describing the

Table 1 Codes related to the definition/description of injury and associated illustrative quotes

Performance limitation
I think an injury can be any sort of limitation; that doesn't allow you to perform or do your job $100 \%$, or can jeopardize a limitation that you have already. In that case, I think any type of limitation that doesn't allow you to perform 100\% should be taking care of, in order to not make it worse. Artist In my mind, an injury would be something that will cause an artist to not be able to do their regular duties. Something that is caused by trauma, but also something else that makes them not able to perform their duty. AD

Something that prohibits you to be in your full potential; for me, it's an injury. Coach

Missing or modifying -Something that makes you stop to do your act, or something that you need to stop to do on stage. training/ shows

That means, you are not able to do what you do for performing.

-When you can't complete your performance. Different Artists, FG(2)

Sometimes we just adapt to our injuries, for example, if you've injured your finger: 'ok, you can't grab so strong, but you still have 4 more fingers to grab'. So, you can compensate, you can adapt to your injuries. Artist

Impact on the show and performance quality

Pain feeling
In my role, as an $A D$, when I hear the word 'injury', my first question is: how does it affect the artist in the show? So, for me, when we talk about injury there are a lot of questions and a lot of possibilities. So, whether the artist is out completely, short term, long term, modified or restricted temporarily or permanently. AD

I think pain can be the guide of injury for some people, but it depends on the individual. Pmed Pain? Depends on the artist and different artists have different level-of-pain thresholds. Coach -Because we are used to work with pain, right?

-Indeed (others say 'right')

-But pain is a sign that something is wrong.

-Pain gives meaning to your life, you know? (everybody laughs)

-If you wake up with no pain, you are dead. Different Artists, FG(1) 
Table 2 Factors related to the injury occurrence and supportive quotes

\section{Daily schedule (ie,} number of rehearsals, time to eat and rest, staging time)

Number of cues*
$\begin{aligned} & \text { Number of rotations } \\ & \text { and backups }\end{aligned}$

Rest/recovery time

Fatigue

\section{Mental load}

But sometimes they try to put all the training in the same day and if you look at it, they don't plan. They (staff) feel that you can go 'till 7, but at 7 I start to warm up 'till 8 and sometimes, many days, I have to eat in $10 \mathrm{~min}$ and do my make-up and all. Artist

So, we try to look at time too. Because even if you were not having a heavy rehearsal sometimes we are just in the theater, from $1 \mathrm{pm}$ to $11 \mathrm{pm}$, This is a long day. Coach

We take into account what their artistic schedule is, we have a lot of extra staging, and this is extra time to their daily workload. AD

It depends on the show too. In some shows, they need to do many cues, you need to be all the time on stage, and I feel you have more injuries. Artist

It's not even about the act sometimes, it is the cues. We are used to the acts but the cues: that's the load. So we need rotations of cues. Artist

Being able to have a happy rotation, prohibit people to get injured. Because everyone is having a day on and a day off consistently, and your body gets recuperated essentially. Artist

When someone else can take that load. In a group act you have people who can help with the load. In my case if she [another artist] is hurt, like a wrist pain, I can do it for her. Artist

Sounds to me that we need to find a way to rest more. Injury prevention for me it's to have a time for my body to relax. Because you can build in to my quadriceps or my gluteal, but if you take my four hours rehearsal and add my two shows and strength and conditioning somewhere... yes, my gluteus need to be stronger but I am exhausted after that. So it's a way to find a balance between rest and somehow be able to maintain all of the shows. Artist

Artists perform and they usually stay up till 2, 3 in the morning. Because they are bumped in adrenaline. They go to sleep late, they wake up late, and if the schedule starts early they don't have enough rest. AD

Also not being mentally in the place can cause injuries. I know because when I had an injury before, I definitely was not in a good mental space, but it came along with fatigue also. AD

Sometimes physically you can be tired but you can still do the show, you know what you are doing and you are concentrated and you can prevent injuries. But when you are mentally tired, the one second that you are not concentrated, this second will push you to the injury. Artist

Fatigue is a factor, because often an accident happens when someone is not $100 \%$ and this person will make a mistake. Or his body is capable for a certain workload and when fatigue works there, the body can't deal with the weight and the injury happens. Coach

Appropriate technique There is a lot of factors. Starting from technique, we also have group acts, so there could be a mistake of somebody else, someone falls from high and you spot him and you get injured from that. It's very easy to get an injury (...)that's why we train people. Coach

Another factor is the lack of technique, we try to improve it to avoid a movement or a mistake that can lead to an injury. Coach

External factors (ie, weather, arena and touring conditions)
Training space, training area, just the demands of be on tour: like jetlag, sleeping patterns, hotel rooms, all can contribute, all that ...they kind of all match together. Pmed

*Minor performances (dancing or acting) during the shows that add to the artists staging time.

${ }^{* *}$ Some acts or cues can be performed by more than one artist and there is a rotation of the artists to play in different roles.

potential injury risk factors, they suggested an interrelation between factors.

@What do you think influences the injury?

Many things... How they [artist] manage their bodies, how they come to the table, what their discipline is, what their work on a daily basis is, in comparison to what they do in preparation, or maintenance for their own career. Mental state, external influences, anything that is not letting them be in tiptop shape in their brains, accidents, things out of our control. Those are the elements that would be direct contributors to an injury. Also, personal problems, distractions, whether they are happy or worried, focused on what they have to do, if it's a team, the environment, just external things that we can't control as well. AD

The injury factor most referred to was the relationship between load and capacity. Workload was perceived as high, but participants also acknowledged that injury risk was related to their capacity to deal with this workload.

But without the proper training, without strengthening to get there, without the proper work ...that causes an injury. Artist

The artists' workload, as a general concept, was constantly mentioned as injury risk factor. Factors that can modify the workload and their interactions were also frequently described. 


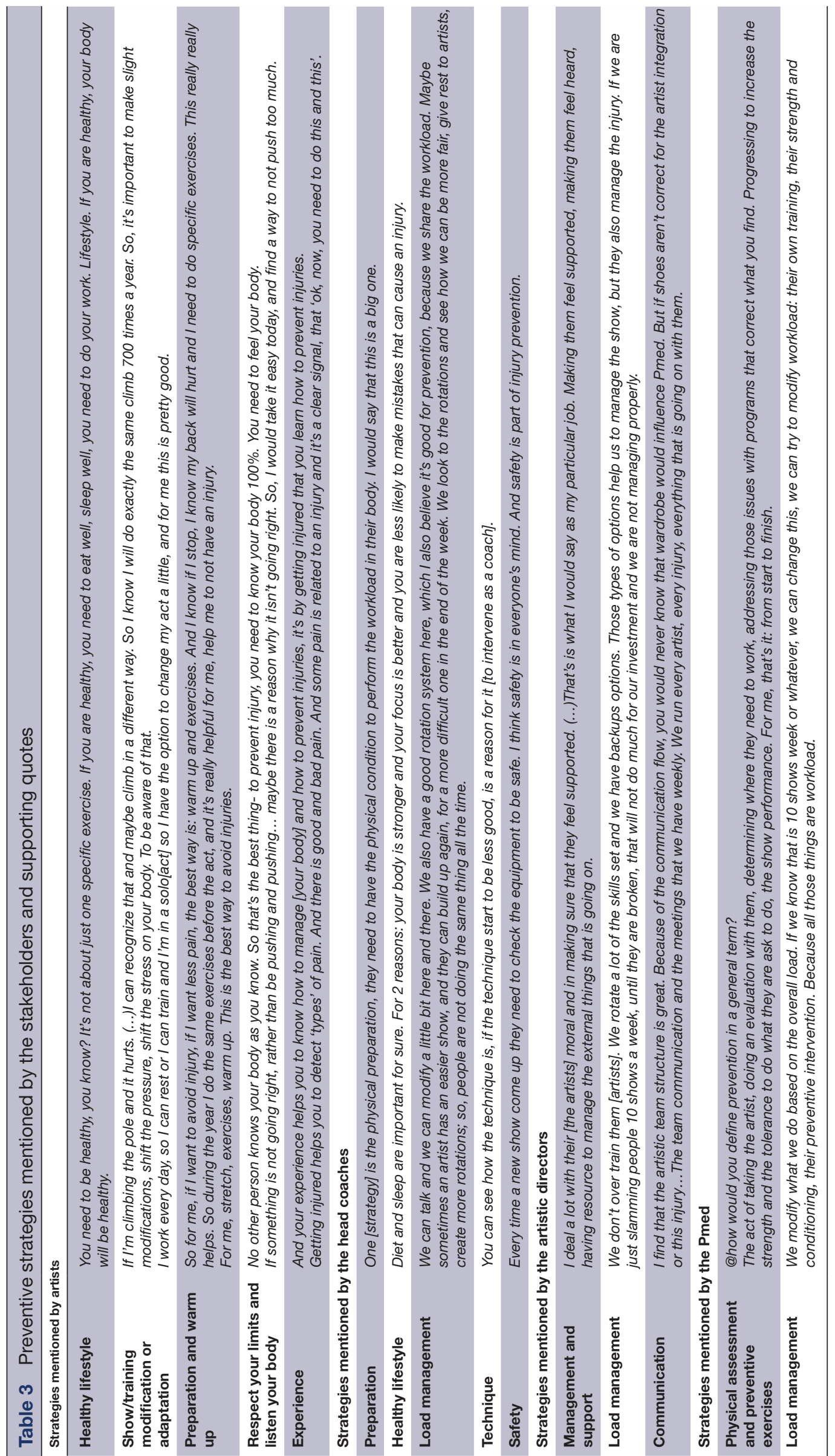


They [artists] need to train to improve technique, to perform better, but we also need to take into consideration that they need to do shows and all the other rehearsal. So we try to balance it, all the time. And it's quite difficult. Coach

Physical workload though was described also to be related with other factors, such as the show schedule and the number of cues. Mental and emotional load were also referred as risk factors for injury. A summary of the main coded injury-related risk factor and associated quotes is presented in table 2 .

\section{Injury prevention: strategies and roles}

All participants described strategies to prevent injuries as part of their practice and also their role (table 3). The artists perceived themselves as responsible for the protection of their health as well as for the injury prevention. Additionally, they stated the need of support from other stakeholders to be able to comply with this responsibility. The artistic team described the artists as the main role for injury prevention as well. However, they also described their own roles and strategies to prevent injuries.

The main preventive strategies described by the artists were maintaining a healthy lifestyle, being fit for their role, performing a proper warm up, listening to their body, respecting limits and managing load. They described injury prevention to be a learning process during which, based on their experiences, they developed their own strategies to prevent future injury. The importance of some of the strategies described by the artists was also underlined by the HCs, ADs and Pmeds, such as preparation, warmup and maintenance of a healthy lifestyle.

The HCs described their injury prevention function in improving technique through training and managing the show and through training workload. To do so, they have to listen to the artist and they have to communicate with the artistic team. Together with the technical team, they also play a role in risk management if it concerns act-specific safety issues.

The ADs acknowledged their role as managers to support injury prevention strategies of other stakeholders and to facilitate the communication between different departments or at the higher organisational level.

For Pmeds, their role to prevent injuries was mainly related to physical assessments and to possible interventions to reduce the risk of injury through exercise-based interventions; that is, preventive exercises. They described their role in load management when providing advice to the artistic team, mainly when it concerned artists at a specific risk or artists being symptomatic or injured.

Other stakeholders who were not interviewed were mentioned as part of injury prevention, while they hold responsibility for factors related to the injuries. For example, the daily schedule and line-up of the show are prepared by stage management (SM) together with the artistic team, which make these stakeholders part of the injury prevention strategy of managing the load (table 4).

Table 4 Other departments roles that influence injury and its prevention

$\begin{array}{ll}\begin{array}{l}\text { Stage management } \\ \text { (SM) }\end{array} & \begin{array}{l}\text { SM, because they are the ones that are dividing the cues. So if they see that an artist is on stage } 75 \% \\ \text { of the time, while this other artist is just } 50 \% \ldots \text { They need to find rotations, backups, replacements } \\ \text { and put that in place in order to balance the load. AD }\end{array}\end{array}$

Technical staff (Sound, Light, Automation)

Wardrobe

Casting

Creation

High management (senior managers)

Travel and lodging/tour management
The technician for our act is very important and you need to trust them. (others agree). It's trust in the technicians and in our team. Artist

Any aerial number it's dangerous for us. So, we need the technical team in their best game. So it's not just artists that need to prevent injuries. Artist

In our costume, we have pads in some areas where we hit the bars and wardrobe always help with that. They put pads to protect these areas. Artist

I'm having this problem with my costume, and for me is not a big safety thing. But I would make a lot easier for me to execute this particular trick if I have a piece of this costume gone. (...)And they need to developed a whole new costume. Artist

Casting- I think it's very important. The choice of that person for that profile. There is a lot of trouble choosing people who are not appropriate for that. And sometimes with a month, a week, the person breaks down. Because the casting was badly done, the way we choose the artists is very important. Coach

Also in creation, you have to be careful when you create certain acts. If they come with an act that the experts of cirque already see: 'uhh, it's a beautiful act right now, but in a long term this might become a problem'. So, they should think about it already there. And hire at least two groups of those people and they can always rotate. So the pressure is not just in a duo or in trio. AD

The thing that I keep talking about is: for me, injury prevention should start in the headquarters. Because it's... something new. (...). It's hard to start without [injury prevention]. This is a big big thing right now. This needs to be part of the culture of circus, the injury prevention. Coach

I believe tour management could help us a lot, in regards to travel to city to city. Some of the times put a lot of stress in my body. (...)l feel like simple measures that could be taken by other departments that could really benefit our health. Artist 


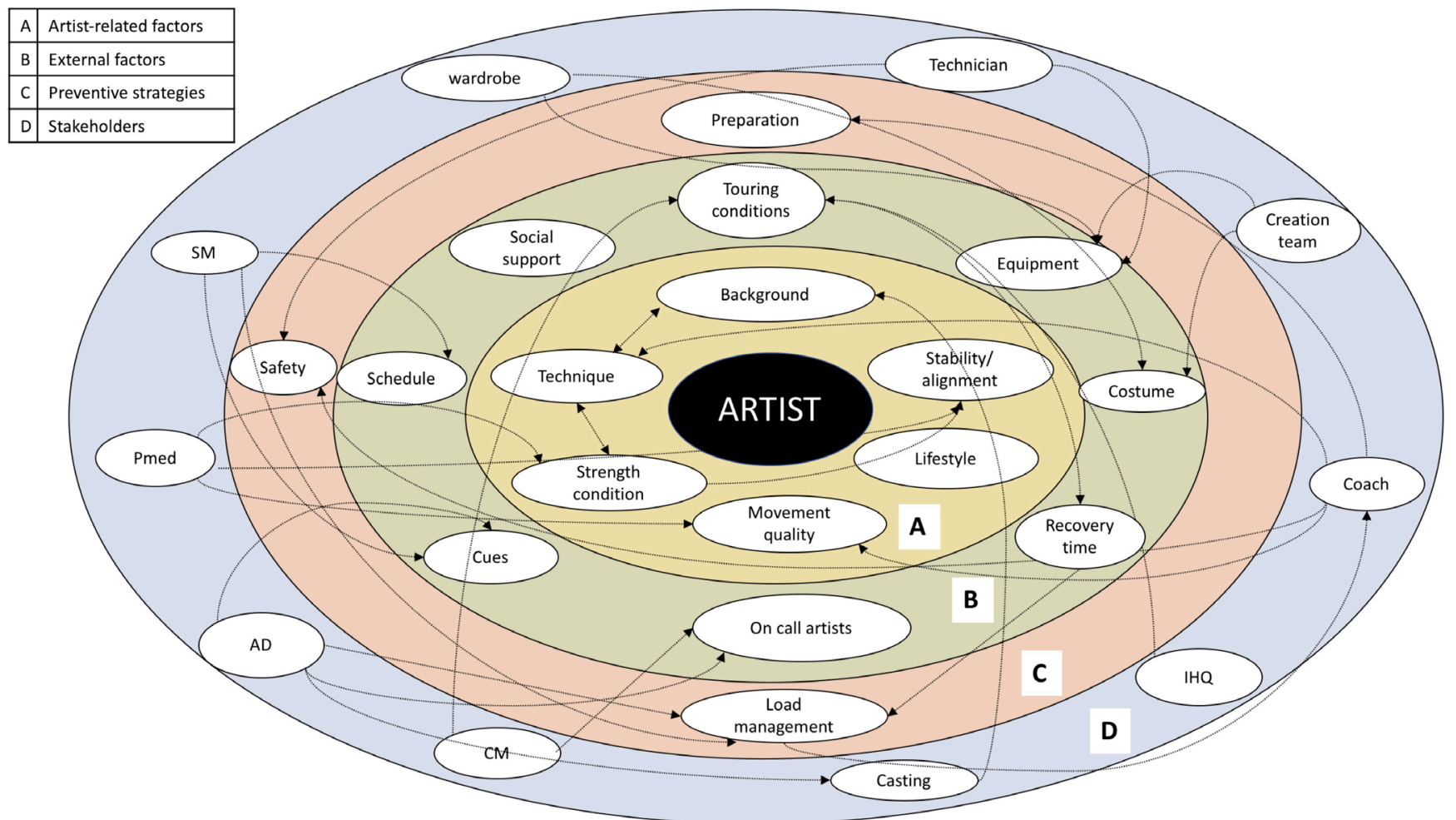

Figure 2 A multilevel system map with factors, strategies and stakeholders in relation to injury and their prevention. Starting at the centre of the map (ie, the athlete) and moving distally; $(A)$ entails artists-related intrinsic injury factors; (B) presents external injury factors; $(C)$ describes the main preventive strategies (eg, load management, safety and preparation) which are driven by the factors from the inner two circles; (D) represents the stakeholders in the system as well as how they connect to the strategies and factors across the multiple levels.

\section{Mapping injury prevention by a system thinking approach}

Initially, a first map was proposed with no guiding framework, being a raw description of interrelations of main codes observed in our data, resulting in a chaotic web of concepts. Thereafter, we applied a systems thinking approach to organise the data in a multiple level system by mapping the main elements, the various stakeholder groups and the interconnectedness between them. We subsequently built a system map with the artist in the centre with subsequent circles around the artist, running from proximal to distal, considering the respective stakeholders as well as their interconnections (figure 2). Circle A, represents mainly artist-related (intrinsic) factors, such as the artist's lifestyle and technique. Circle B presents external factors related to injury prevention, for example, the show schedule. The elements of the circles A and B build up to circle $\mathrm{C}$, with the main prevention strategies. For instance, preparation depends on equipment and also on the artist's strength condition. Thereafter, circle D represents the different stakeholders who are connected to the strategies and the factors in different levels. Load management, as an example, is a multilevel strategy that connects to many stakeholders who can modulate different elements that comprise load, such as schedule or movement quality.

\section{DISCUSSION}

This study captured an overview of injury and its prevention in the unique context of an international circus company and analysed from a systems thinking lens.

\section{Injury is defined based on performance limitation}

The way that injury was described was mainly based on the consequence that injury has on performance. Missing or modified performances and the need for medical care are typically the main criteria applied in the current injury reporting system in Cirque du Soleil, ${ }^{1}$ which suggest that injuries may be underreported if we consider the stakeholders' definition. Injury definition was already discussed in the dance and sports medicine literature, ${ }^{20-22}$ also reflecting on the potential underreporting when applying time-loss definitions. Monitoring the level of performance of the artist from a stakeholders' perspective can be a potential way to monitor injuries and their consequence. Pain was not directly associated with injury, as the artists perceived pain as 'part of the game'. Studies with dancers and elite athletes ${ }^{23}{ }^{24}$ have already stated that pain is perceived as trivial, which is similar to the perceptions presented in our study.

\section{Workload plays an important role}

The workload was presented as the main injury risk, but also modulated by interrelated factors (eg, schedule, 
cues and number of rotations). In line, the importance of load was mentioned by the participants, who stated load management as a preventive strategy. All stakeholders mentioned their role in load management and they also described the role of other stakeholders (ie, SM). In this way, as some sports medicine studies have already suggested, load management is an important strategy for injury prevention..$^{25}$ The literature also emphasises the need for an open communication ${ }^{27}$ and shared responsibility $^{28}$ in load management. Hereby, the AD's role of team manager and leader is also a relevant to support injury prevention strategies. If we draw a parallel with sports, the head coach is the leader and there is evidence that the leadership style can influence the injury occurrence. ${ }^{29}$

\section{Injury prevention in a multilevel system}

Systems thinking ${ }^{19}$ helps us to understand how the elements that relate to injury and its prevention are under control of different stakeholders. Beyond the stakeholders that are directly related to the artist such as coach and Pmed, there are other departments (eg, high management) which indirectly affect key elements of injury prevention in a multilevel system. Therefore, to develop more comprehensive injury prevention strategies, all stakeholders should be involved and engaged, by acknowledging how their roles potentially impact injury and its prevention. Moreover, the interconnected levels indicate the importance of shared responsibility regarding injury prevention. This teamwork needs to be structured, understood and reinforced.

However, although a system map helps to understand the complexity of injury prevention in practice, it is just a starting point. Considering injury prevention as a dynamic and complex system, for a deeper understanding, we need to be able to monitor how the elements work and interact in the system and how they change over time.

\section{Strengths and limitations}

This study has some limitations. This very specific sample limits comparability with other settings. Despite our guarantee of confidentiality, it is possible that some participants filtered their opinions, as they are company employees. Moving to strengths, we included four different stakeholder groups ( $\mathrm{AD}$, coaches, health professionals), who provided multiple perspectives on injury prevention. We applied concepts of the Grounded Theory which allowed findings to emerge from the data and describe the participant's perspectives. Additionally, by applying qualitative research and system thinking principles, we developed an innovative approach that may help to further develop the field; it may be useful in other sport medicine settings.

\section{CONCLUSION}

By applying qualitative methods and a systems thinking approach, we mapped injury prevention in daily practice, thereby allowing us to better understand the challenges and opportunities in this particular setting.
Injury prevention was presented as a multilevel system that involves diverse stakeholders. This reinforces the importance of multilevel injury prevention approaches with shared responsibility and open communication between stakeholders. Since the company in this study can be compared with some sports organisations, we encourage future studies to apply a similar approach in sports settings.

\section{Author affiliations}

${ }^{1}$ Amsterdam Collaboration for Health \& Safety in Sports, Amsterdam UMC, Vrije Universiteit Amsterdam, Department of Public and Occupational Health, Amsterdam Public Health Research Institute, Amsterdam, The Netherlands

${ }^{2}$ Vegas Golden Knights, National Hockey League, Las Vegas, Nevada, USA ${ }^{3}$ UCT/MRC Research Unit for Exercise Science and Sports Medicine (ESSM), Department of Human Biology, Faculty of Health Sciences, University of Cape Town, Cape Town, South Africa

${ }^{4}$ School of Public Health, Physiotherapy and Population Sciences, University College Dublin, Dublin, Ireland

${ }^{5}$ School of Human Movement and Nutrition Sciences, Faculty of Health and Behavioural Sciences, University of Queensland, Brisbane, Queensland, Australia

Acknowledgements The authors would like to thank Cirque du Soleil for supporting this study.

Contributors $\mathrm{CB}$ developed the reasoning for this paper and drafted the first version. JM, EV, WvM and HRP contributed intellectually and provided feedback on various drafts.

Funding $\mathrm{CB}$ is a $\mathrm{PhD}$ candidate supported by Conselho Nacional de Desenvolvimento Científico e Tecnológico-CNPq, Brazil, grant number 202242/2015-3. No other sources of funding were used to assist in the preparation of this article.

Competing interests CB and JM are former employees of Cirque du Soleil. EV is a consultant of Cirque du Soleil.

Patient consent for publication Not required.

Ethics approval This study was approved by VU University Medical Center Ethics Committee, Amsterdam, the Netherlands; protocol METc FWA00017598.

Provenance and peer review Not commissioned; internally peer reviewed.

Open access This is an open access article distributed in accordance with the Creative Commons Attribution Non Commercial (CC BY-NC 4.0) license, which permits others to distribute, remix, adapt, build upon this work non-commercially, and license their derivative works on different terms, provided the original work is properly cited, appropriate credit is given, any changes made indicated, and the use is non-commercial. See: http://creativecommons.org/licenses/by-nc/4.0/.

\section{REFERENCES}

1. Shrier I, Meeuwisse WH, Matheson GO, et al. Injury patterns and injury rates in the Circus arts: an analysis of 5 years of data from Cirque Du SOLEIL. Am J Sports Med 2009;37:1143-9.

2. Wolfenden HE, Angioi M. Musculoskeletal injury profile of Circus artists: a systematic review of the literature. Med Probl Perform Art 2017;32:51-9.

3. Orlando C, Levitan EB, Mittleman MA, et al. The effect of rest days on injury rates. Scand J Med Sci Sports 2011;21:e64-71.

4. Manchester RA. Toward Better prevention of injuries among performing artists. Med Probl Perform Art 2006;21.

5. É L, Cloutier E, Ouellet F, et al. Occupational Risks in the Performing Arts: An Exploratory Study. In: Institut de Recherche Robert-Sauvé en santé et en sécurité Du travail IRSST, 2009.

6. Bittencourt NFN, Meeuwisse WH, Mendonca LD, et al. Complex systems approach for sports injuries: moving from risk factor identification to injury pattern recognition-narrative review and new concept. Br J Sports Med 2016;50:1309-14.

7. Bekker S, Clark AM. Bringing complexity to sports injury prevention research: from simplification to explanation. $\mathrm{Br} J$ Sports Med 2016;50:1489-90.

8. Bolling C, van Mechelen W, Pasman HR, et al. Context Matters: Revisiting the First Step of the 'Sequence of Prevention' of Sports Injuries. Sports Med 2018;48:0123456789:2227-34. 
9. van Mechelen W, Hlobil H, Kemper HC. Incidence, severity, aetiology and prevention of sports injuries. A review of concepts. Sports Med 1992;14:82-99.

10. Luke DA, Stamatakis KA. Systems science methods in public health: dynamics, networks, and agents. Annu Rev Public Health 2012;33:357-76.

11. de Savigny D, Adam T, eds. Systems thinking for health systems strengthening, Alliance HPSR. Geneva, Switzerland: WHO, 2009.

12. Cirque du Soleil- Official website [Internet]. Available: https://www. cirquedusoleil.com/about/history

13. Wikipedia. Wikipedia- Cirque du Soleil [Internet]. Available: https:// en.wikipedia.org/wiki/Cirque du Soleil

14. Strauss A, Corbin JM. Basics of qualitative research: Grounded theory procedures and techniques. . Newbury, 2008: 3. 379.

15. Charmarz K. Constructing Grounded Theory: A Practical Guide through Qualitative Analysis. London: Sage Publications, 2006.

16. Glaser BG. The constant comparative method of qualitative analysis. Soc Probl 1965;12:436-45.

17. Boeije $\mathrm{H}$, Boeije $\mathrm{H}$. A purposeful approach to the constant comparative method in the analysis of qualitative interviews. Qual Quant 2002;36:391-409.

18. Daley BJ. Using concept maps in qualitative research. In: Concept maps theory, Methodol Technol proC first int Conf concept Mapp. 2004: 1, 191-9.

19. Leischow SJ, Milstein B. Systems thinking and modeling for public health practice. Am J Public Health 2006;96:403-5.

20. Kenny SJ, Palacios-Derflingher L, Whittaker JL, et al. The influence of injury definition on injury burden in Preprofessional ballet and contemporary dancers. J Orthop Sports Phys Ther 2018;48:185-93.
21. Timpka T, Jacobsson J, Bickenbach J, et al. What is a sports injury? Sports Med 2014;44:423-8.

22. Bahr R. No injuries, but plenty of pain? On the methodology for recording overuse symptoms in sports. Br J Sports Med 2009;43:966-72.

23. Tajet-Foxell B, Rose FD. Pain and pain tolerance in professional ballet dancers. Br J Sports Med 1995;29:31-4.

24. Tesarz J, Schuster AK, Hartmann M, et al. Pain perception in athletes compared to normally active controls: a systematic review with meta-analysis. Pain 2012;153:1253-62.

25. Gabbett TJ. The training-injury prevention paradox: should athletes be training smarter and harder? Br J Sports Med 2016;50:273-80. LP.

26. Dijkstra HP, Pollock N, Chakraverty R, et al. Managing the health of the elite athlete: a new integrated performance health management and coaching model. $\mathrm{Br} J$ Sports Med 2014;48:523-31.

27. Ekstrand J, Lundqvist D, Davison $\mathrm{M}$, et al. Communication quality between the medical team and the head coach/manager is associated with injury burden and player availability in elite football clubs. Br J Sports Med 2018. [Published Online First: 13 August 2018].

28. Coles PA. An injury prevention pyramid for elite sports teams. $\mathrm{Br} J$ Sports Med 2018;52:1008-10.

29. Ekstrand J, Lundqvist D, Lagerbäck L, et al. Is there a correlation between coaches' leadership styles and injuries in elite football teams? A study of 36 elite teams in 17 countries. Br J Sports Med 2018;52:527-31. 